\title{
Hormigoi armatuaren eboluzioa linealki irakurtzeko ezintasuna. Espainiaren kasua (1896-1973)
}

\author{
(The impossibility of the linear reading of the evolution of \\ reinforced concrete. The case of Spain (1896-1973)) \\ Maialen Sagarna ${ }^{1 *}$, Lauren Etxepare ${ }^{1}$, Iñigo Lizundia ${ }^{1}$, \\ Eneko Jokin Uranga ${ }^{2}$ \\ ${ }^{1}$ Arkitekturan doktore eta irakasle UPV/EHUn, Donostian \\ ${ }^{2}$ Arkitekto eta Irakasle UPV/EHUn, Donostian \\ * maialen.sagarna@ehu.eus
}

DOI: 10.1387/ekaia.17746

Laburpena: Material artifizial baten kalitateak garaiz garai duen bilakaerak ez luke atzerakadarik izan behar. Garapen teknologikoak eta erabileraren jarraipenak bermatu beharko lukete kalitatearen hobekuntza, baldin eta egia balitz teknologiak eta zientziak, bide beretik, norabide berean eta abiadura berarekin egiten dutela beti aurrera. Alabaina, gertaera sozioekonomiko eta politikoek baldintzatu dezakete bilakaera hori, material baten teknologiaren eta ezaugarrien eboluzioa linealki irakurtzea ezinezko bihurtuz. Horren adibide garbia da Espainian hormigoi armatuak izan duen bilakaera. Artikulu honek hori azaltzea du helburu, Euskal Herrian aspaldian eraikitako hainbat egitura historikotan eskuraturiko datuak elkarren parean jarriz eta kronologikoki aztertuz.

Hitz gakoak: hormigoi armatua, historia, kalitatea, patenteak, araudia, murriztapenak.

\begin{abstract}
The evolution of the quality of an artificial material in subsequent periods should not present setbacks. Technological development and monitoring the execution should ensure a favourable outcome in quality. However, socioeconomic and political forces can distort the course of this evolution, making it impossible for a linear reading; serving as an example of this is the history of reinforced concrete in Spain. The purpose of this article is to explain this evolution, comparing and analyzing chronologically the data obtained from a series of structures built in the Basque Country in the past.
\end{abstract}

Keywords: concrete, history, quality, patents, regulations, restrictions. 


\section{SARRERA}

XX. mendeko arkitekturan berrikuntza handiena ekarri zuen materiala da hormigoi armatua. Egurrak, harriak eta altzairuak ez dituzten propietateak eskaintzen ditu eta horrek arkitektura egiteko modu berriak ekarri zituen. Gaur egun eraikuntzan gehien erabiltzen den materiala da, baina, beste edozein materialek bezala, deboran zehar higadura jasaten du, eta beraz, zaharberritze-lanak ezinbestekoak dira bere funtzionaltasuna eta osotasuna bermatzeko.

Zaharberritzerako nahitaezkoa da materialaren nondik norakoak ezagutzea. Izan ere, jasango dituen kalteak garaian garaiko materialaren propietateekin, eta beraz, kalitatearekin lotura zuzena baitute.

Berez, material artifizial baten kalitateak garaiz garai duen bilakaerak ez luke atzerakadarik izan behar. Garapen teknologikoak eta erabileraren jarraipenak bermatu beharko lukete kalitatearen hobekuntza, baldin eta egia balitz teknologiak eta zientziak, bide beretik, norabide berean eta abiadura berarekin egiten dutela beti aurrera. Alabaina, gertaera sozioekonomiko eta politikoek baldintzatu dezakete bilakaera hori, material baten teknologiaren eta ezaugarrien eboluzioa linealki irakurtzea ezinezko bihurtuz. Horren adibide garbia da Espainian hormigoi armatuak izan duen bilakaera. Artikulu honek hori azaltzea du helburu, Euskal Herrian aspaldian eraikitako hainbat egitura historikotan eskuraturiko datuak [1] elkarren parean jarriz eta kronologikoki aztertuz. Eraikinak aukeratzeko irizpide nagusia eraikitze-data izan da.

\section{HORMIGOI ARMATUAREN SARRERA ESPAINIAN (1893-1939)}

Antzinako zibilizazioen garaietatik erabiltzen dira harri-zatikiak aglomeratzaile baten bidez batuz eraturiko materialak, baina gaur egun ezagutzen dugun hormigoi armatuaren erabilera normalizatua Portland zementua deritzon zementu artifizialaren ekoizpen industrialarekin etorri zen.

JosephAspdin-ek 1824an patentatu zuen artifizialki ekoitzitako zementu hori, baina Espainian ez zen produkzio industrialik izan XIX. mendearen bukaera aldera arte: TudelaVeguin Asturiasen (1898), Cementos Rezola Gipuzkoan (1900), Compañía General de Asfaltos y Portland Asland, S.A. Katalunian (1901) izan ziren ekoizten lehenak.

Garai horretantxe hasi ziren konglomeratua eta burdina konbinatzen, edozein motatako eraikuntzen trakzio-esfortzuei erantzuteko erresistentzia lortzeko. Material horren erabilera mundu osoan zehar zabalduz joan zen «isilpeko» patenteen bitartez. Lehen bi patente garrantzitsuenak (Monier eta Hennebique, ikus 1. irudia) 1893an FrancescMaciàren (Monier-en pa- 
tentearen kontzesionarioa) eta 1898an José Antonio Riberaren (Hennebiqueren patentearen kontzesionarioa) eskutik etorri ziren.
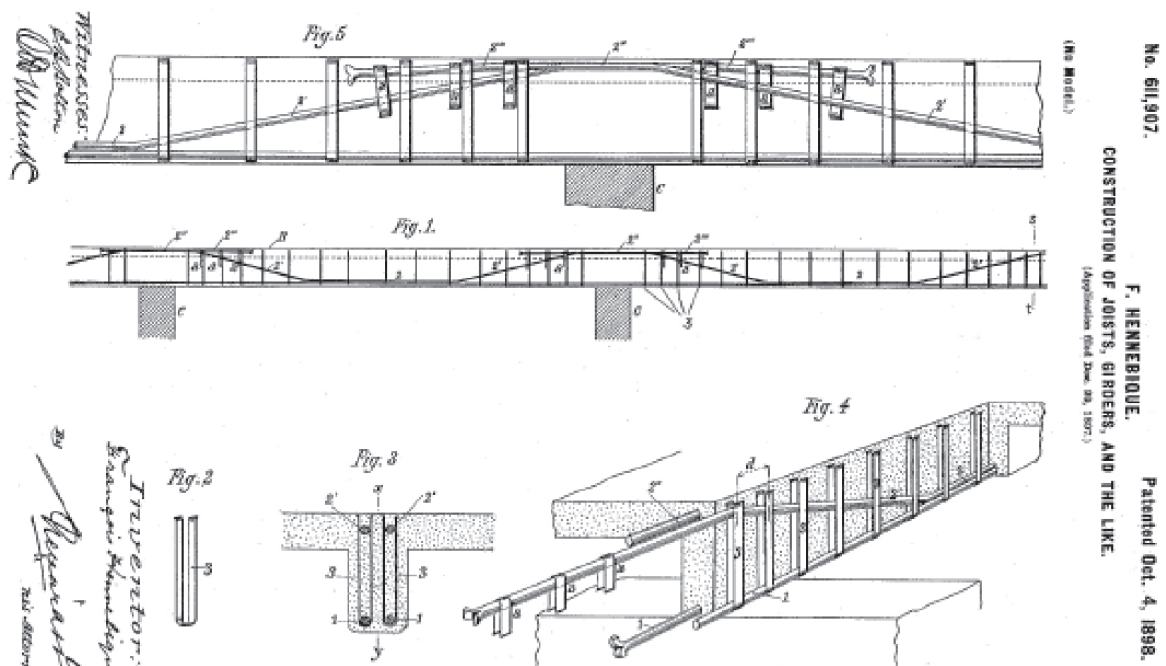

1. irudia. Hennebiqueren patentea. Iturria: L'invention du bétonarmé : Hennebique 1890-1914 / par GwenaëlDelhumeau.

Hala ere, artean, ez zuten benetan ezagutzen material horren funtzionamendua, eta, batez ere, lan intuitiboak eta esperimentalak ziren. Hortaz, material berriarekin egin ziren lehen obrak kalkulurik, diseinurik edo exekuzioa gidatzeko araudirik gabe egin ziren.

Konfiantza itsu-itsua zuten material berrian, eta asko estimatzen zituzten suaren kontrako jarkikortasuna (abantaila handia baitzuen ordura arte, oro har, erabili ziren altzairuzko egituren aldean), irazgaiztasuna, ekonomia eta higienea. Xx. mendearen lehen hamar urteetan, Espainian, materiala, batez ere, herri-lanetan, ekipamenduetan eta fabriketan erabili zuten. Materiala «errezeta» horietan oinarrituta erabiltzen jarraitu zuten XX. mendearen lehen herenean.

Kalitate-kontrolari dagokionez, garai hartan, hormigoiaren kalitatea begiz jota eta erabilerak eman zien eskarmentuaz baliatuz neurtzen zen. Hormigoiarentzako berariazko saiakuntza-ekipamendurik ez zegoen ia.

1936an, Gerrate Zibilarekin, eraikuntza-industriak geldialdia izan zuen; 1936 eta 1938 bitartean eraikin askoren eraikuntza gelditu egin zen.

Gerraosteko sistema ekonomikoa gero eta interbentzionismo ekonomiko handiagoan oinarritu zen, berrarmatzea beste helbururik gabe (estatu 
totalitarioei, hau da, Italiari eta Alemaniari laguntzeko), hiriak berreraikitzea bezalako beste edozein eginkizunen kaltetan.

José María de Areilzak, Francoren administrazioan goi-mailako karguak izan zituenak, honako hitzaldi hau [2] eman zuen 1940an:

«En el desarrollo de una política autárquica (...) reside la clave del porvenir económico de España. No hay en rigor otro plan auténtico de reconstrucción nacional, sino éste: el que mira hacia fuera. Y sería lamentable equivocación suponer que la gran empresa reconstructora de la postguerra, se limite a la reedificación urbana de unas cuantas poblaciones destruidas por la metralla, o a la restauración de obras públicas voladas por la dinamita roja. Ello es necesario y es indispensable (...) pero en fin de cuentas, lo que importa, sobre todo, es nuestra autarquía, es decir, la base de una total libertad exterior de España ante el mundo.»

Hormigoi armatuz garai horretan eraikitako zenbait eraikin aztertu dira [3]. Egin diren konpresio-erresistentziaren saiakuntzen emaitzak 1. taulan ikus daitezke.

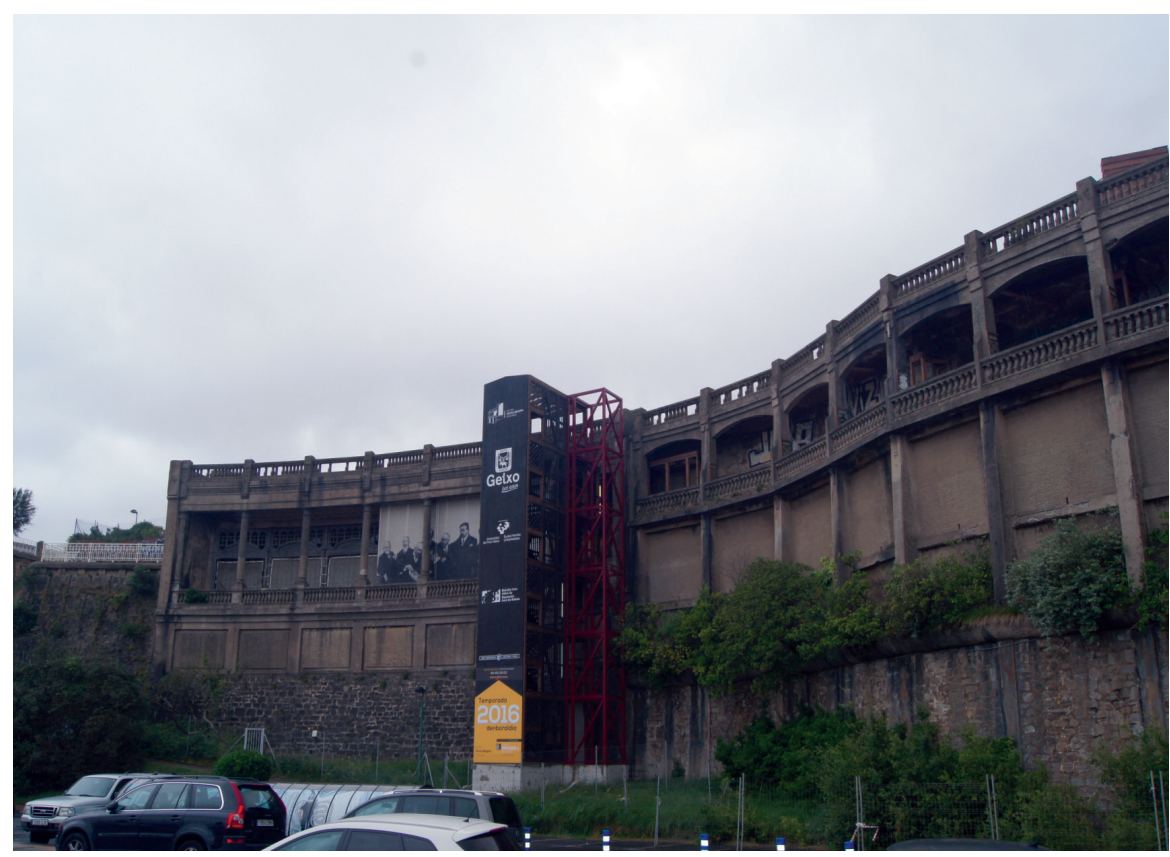

2. irudia. Getxoko Punta Begoñako galerien ipar-mendebaldeko fatxada. Gaur egungo egoera. 1919an Eraikia Ricardo Bastida Arkitektoaren zuzendaritzarekin. 
1. taula. Batez besteko erresistentzia eta erresistentzia bereizgarria konpresioarenaren aurrean. 1901 eta 1934 bitartean eraikitako eraikinak.

\begin{tabular}{|c|c|c|c|c|}
\hline $\begin{array}{l}\text { Eraikitako } \\
\text { urtea }\end{array}$ & $\begin{array}{c}\text { Erresistentzia } \\
\text { bereizgarria } \\
\mathrm{N} / \mathrm{mm}^{2}\end{array}$ & $\begin{array}{l}\text { Batez besteko } \\
\text { erresistentzia } \\
\mathrm{N} / \mathrm{mm}^{2}\end{array}$ & Eraikina & $\begin{array}{l}\text { Txostenaren } \\
\text { jatorria [1] }\end{array}$ \\
\hline 1901 & 16,56 & 12,25 & $\begin{array}{l}\text { La Ceres irin-fabrika } \\
\text { (Bilbo) }\end{array}$ & $\begin{array}{l}\text { Aurrekoetxea et al., } \\
\text { GIKESA }\end{array}$ \\
\hline 1903 & 15,09 & 9,31 & $\begin{array}{l}\text { Zarauzko merkatua } \\
\text { (Zarautz) }\end{array}$ & $\begin{array}{l}\text { Santamaria et al., } \\
\text { GIKESA }\end{array}$ \\
\hline 1909 & 17,44 & 12,05 & $\begin{array}{l}\text { Bilboko alondegia } \\
\text { (Bilbo) }\end{array}$ & $\begin{array}{l}\text { Suarez et al., } \\
\text { LABEIN }\end{array}$ \\
\hline 1910 & 23,91 & 25,48 & $\begin{array}{l}\text { Victoria Erregina Mi- } \\
\text { serikordi etxea } \\
\text { (Donostia) }\end{array}$ & $\begin{array}{l}\text { Aurrekoetxea et al., } \\
\text { GIKESA }\end{array}$ \\
\hline 1916 & 18,33 & 9,41 & $\begin{array}{l}\text { Etxebizitza eraikina } \\
\text { (Donostia) }\end{array}$ & $\begin{array}{l}\text { Aurrekoetxea et al., } \\
\text { GIKESA }\end{array}$ \\
\hline 1918 & 26,56 & 20,29 & $\begin{array}{l}\text { Zankoeta desinfek- } \\
\text { zioa zentroa } \\
\text { (Bilbo) }\end{array}$ & $\begin{array}{l}\text { Ezquerro et al., } \\
\text { LABEIN }\end{array}$ \\
\hline 1919 & 22,54 & 9,51 & $\begin{array}{l}\text { Punta Begoña gale- } \\
\text { riak } \\
\text { (Getxo) (2. irudia) }\end{array}$ & $\begin{array}{l}\text { San Mateos et al., } \\
\text { LABEIN }\end{array}$ \\
\hline 1922 & 22,83 & 18,62 & $\begin{array}{l}\text { VillaDucourau } \\
\text { (Irun) }\end{array}$ & $\begin{array}{l}\text { Marcos et al, } \\
\text { LABEIN }\end{array}$ \\
\hline 1924 & 24,40 & 23,03 & $\begin{array}{l}\text { Etxebizitza eraikina } \\
\text { (Santurtzi) }\end{array}$ & $\begin{array}{l}\text { Fernandez et al., } \\
\text { LABEIN }\end{array}$ \\
\hline 1929 & 27,44 & 17,25 & $\begin{array}{l}\text { Erriberako merkatua } \\
\text { (Bilbo) }\end{array}$ & $\begin{array}{l}\text { Lasarte et al., } \\
\text { LABEIN }\end{array}$ \\
\hline 1934 & 30,58 & 14,80 & $\begin{array}{l}\text { Etxebizitza eraikina } \\
\text { (Bilbo) }\end{array}$ & $\begin{array}{l}\text { Lasarte et al., } \\
\text { LABEIN }\end{array}$ \\
\hline
\end{tabular}

\section{GERRAOSTEA (1939-1960)}

Gerraostearekin patenteen gainbehera iritsi zen. Europa osoan zehar, hormigoi armatuaren erabilerari buruzko tratatuak eta arauak agertuz joan ziren. 
Izan ere, ingeniari batzuek oinarri zientifikoa zuten teoriak garatu zituzten, isilpeko patenteak baztertzen hasi ziren, eta hormigoi armatuzko elementuei buruzko tratatu zientifikoetan oinarritzen hasi. Araudi baten beharra argi geratu zen, ikusi zutenean garatzen hasiak ziren kalkuluek lege batzuk bete behar zituztela. Tratatuak eta araudiak argitaratu ahala, patenteak desagertzen joan ziren.

Hormigoi armatua produktu bat izatetik ingeniariek, arkitektoek eta eraikitzaileek eskura zuten teknika bat izatera pasatu zen.

Alabaina, Xx. mendearen hasieran bertan, Frantziak (1906) eta Alemaniak (1904) hormigoi armatuari buruzko araudiak argitaratu zituzten arren, Espainian 1939 arte ez zen argitara eman material berriaren erabilera erregulatuko zuen lehen araua: «Instrucción para el proyecto y ejecución de obras de hormigón».

Aldi berean, herrialdeak gerraostean zuen egoera larriak Estatua eraikuntza-industrian eragin zuzena izango zuten neurri arauemaileak hartzera behartu zuen. Testuinguru horretan jarri zen abian Berreraikitze-plan Nazionala, material batzuen erabilera mugatzen zuena, eta interes nazionaleko beste industria batzuetan erabiltzeari lehentasuna ematen ziona. 1941ean burdina erabiltzeari mugak ezartzen zizkion lehen dekretua atera zuten [4], urte berean garatu zutena zegokion erregelamenduarekin, eraikuntzan kontuan izan beharreko baldintzak zehazten zituena.

1943an bi agindu gehitu zituzten eraikinen eraikuntzan burdina erabiltzeari [5] eta zementuz hornitzeko lehentasunari buruzkoak, ahalik eta materialen kopururik txikienak erabiltzeko eta aurrezkirik handienak lortzeko helburuarekin. Horrek merkatu beltza agertzea eragin zuen, materialen kuota handiagoak lortzeko garestiago ordainduz.

Erregelamendu eta agindu horiek guztiek eraikitako obren kalitatea gutxitu zuten, obren iraunkortasunaren kaltetan. Gainera [6], une hartako industriaren baldintzek ez zuten aukerarik ematen materialen ekoizpen-prozesuen kalitate-kontrolak egiteko, eta kalkuluak justu-justukoak ziren. Horren eraginez, neurri horiek indarrean egon ziren 20 urteetan eraikitako eraikinak oso kalitate txarraz eraikiak eraiki ziren, eta oso laster zaharkiturik geratu ziren.

Garai hartan ezarritako produkzio-sistemaren errealitate ekonomikoak produkzio industrialaren kalitatean eraikuntza-sektorearentzat izan zituen ondorio tamalgarrien lekukotasuna eskaintzen digu Eraikuntzaren eta Zementuaren Institutu Teknikoaren zuzendari zen Jaime Nadalek gogorarazi zuenak 1959an. [7]:

«(...) lo que hasta entonces era evolución, se convirtió en carrera, en carrera de precios, de oportunidades, de velocidad de circulación dineraria, 
de acumulación de materiales, y en suma, también, en una carrera de producción sin calidad, porque la velocidad era tal, que la calidad encarecía y aquel que pretendí aobtenerla corría el peligro de sucumbir por la competencia de alguno que vendía lo mismo, pero más barato, aunque fuese peor.» «La calidad media bajó en todo o en casi todo, mientras que en Europa subía lentamente, pero subía. (...) la realidad es que las diferencias se acentuaban.»

Estatuaren azken helburua zen altzairuaren erabilera saihestea eraikuntzan [8], eta hormigoi armatuaren erabilera sustatzea, baina mugetaraino eramandako hormigoi batena, oso kalitate txarrekoa, fabrikazioan nahiz obran jartzean.

Espainiako teknikariek 1947az geroztik industriak landutako artikuluen kalitatea hobetzeko eskatzen zuten. 1952an irailaren 26ko Dekretua agertu zen, kalitate industrialeko arauak ezartzen zituena.

Zementuaren ekoizpena asko handitu zen 1940ko hamarkadaren bukaera aldera, eta altzairuarena 1950eko hamarkadaren erdialdera, eraikuntzak hartu zuen martxa azkarraren ondorioz.

Hala ere, artean, altzairua eraikuntzan erabiltzea mugatzen zuen Dekretua [9] indarrean zegoen, eta horrek, zementuaren hornikuntza areagotzearekin batera, hormigoi armatuzko argi txiki eta ertaineko egituren garapenaren alde jokatu zuen.

Eraikuntzako materialen merkatu beltza indarra galduz joan zen, oinarrizko materialen eskaintza handitu eta eskuartze-organismoen eskumenak gutxitu ahala.

Garai horretan hormigoi armatuz eraikitako eraikin batzuk aztertu dira. Egin diren konpresio-erresistentziaren saiakuntzak 2. taulan ikus daitezke. 
2. taula. Konpresioaren kontrako batez besteko erresistentzia eta erresistentzia bereizgarria. 1946-1958 bitartean eraikitako eraikinak.

\begin{tabular}{cccll}
\hline $\begin{array}{c}\text { Eraikitako } \\
\text { urtea }\end{array}$ & $\begin{array}{c}\text { Erresistentzia } \\
\text { berizgarria } \\
\mathrm{N} / \mathrm{mm}^{2}\end{array}$ & $\begin{array}{c}\text { Batez besteko } \\
\text { erresistentzia } \\
\mathrm{N} / \mathrm{mm}^{2}\end{array}$ & \multicolumn{1}{c}{ Eraikina } & \multicolumn{1}{c}{$\begin{array}{c}\text { Txostenaren } \\
\text { jatorria [1] }\end{array}$} \\
\hline 1946 & 19,15 & 20,11 & $\begin{array}{l}\text { Etxebizitza eraikina } \\
\text { (Donostia) }\end{array}$ & $\begin{array}{l}\text { Santamaria et al., } \\
\text { GIKESA }\end{array}$ \\
\hline 1950 & 10,88 & 16,48 & $\begin{array}{l}\text { Guardia Zibilaren kuar- } \\
\text { tela } \\
\text { (Aretxabaleta) }\end{array}$ & $\begin{array}{l}\text { Araquistain et al., } \\
\text { GIKESA }\end{array}$ \\
\hline 1951 & 14,49 & 19,48 & $\begin{array}{l}\text { Berazubi estadioa } \\
\text { (Tolosa) }\end{array}$ & $\begin{array}{l}\text { Santamaria et al., } \\
\text { GIKESA }\end{array}$ \\
\hline 1955 & 7,30 & 7,30 & $\begin{array}{l}\text { Etxebizitza eraikina } \\
\text { (Trintxerpe) }\end{array}$ & $\begin{array}{l}\text { Santamaria et al., } \\
\text { GIKESA }\end{array}$ \\
\hline 1958 & 11,24 & 21,01 & $\begin{array}{l}\text { Vista Alegre dorrea } \\
\text { (Zarautz) (3. irudia) }\end{array}$ & $\begin{array}{l}\text { Losañez et al., } \\
\text { GIKESA }\end{array}$ \\
\hline
\end{tabular}

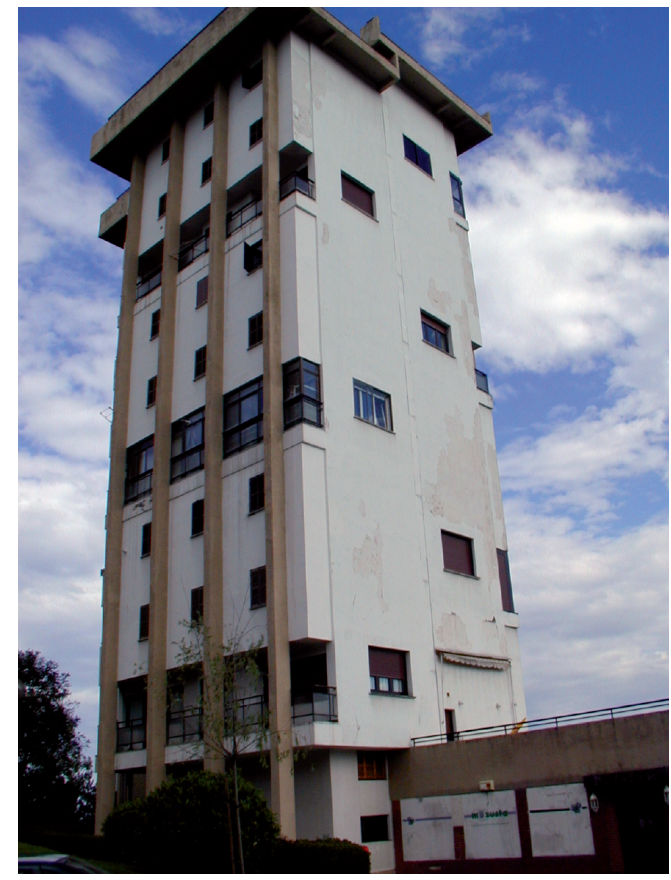

3. irudia. Zarauzko Vista Alegre eraikina. Gaur egungo egoera. 1958an Luis Peña Ganchegui arkitektoak eraikia. 


\section{MURRIZTAPENAK GAINDITZEA (1960-1973)}

Geroago, 1960ko hamarkadan, behin murriztapenak gainditu eta gero, materialen kalitatea hobetzen hasi zen. 1961ean Eraikuntzako Eduardo Torroja Institutuak H.A. 61 araua, hormigoi armatuzko egituretarako berezia, argitaratu zuen, $130 \mathrm{kp} / \mathrm{cm}^{2}$-ko gutxieneko erresistentzia bereizgarria gomendatzen zuena. Garai hartako kalkulugileek arau hori jarraitu zuten arren, testuak ez zuen legezko balio ofizialik.

Hortik aurrera, zenbait dekretu eta agindu argitaratu ziren, materialen eta eraikuntza-prozesuen kalitatea arautzeko [10]

- 1964: konglomeratzaile hidraulikoak; horien produkzioa normalizatzea eta kalitatea bermatzea sustatzeko neurriak. Industria Ministerioaren 1964/06/24ko Agindua (1966an agertu zen agindu hori aplikatzeko Instrukzioa)

- 1968: Masako hormigoia edo armatua erabiliko diren obren proiekturako eta haien exekuziorako Instrukzioa. Bi urteko probarako instrukzio gisa agertu zen, baina benetan 1973 arte luzatu zen.

- Azken araudi horrek konpresio-erresistentzia bereizgarriaren gutxieneko balioa $120 \mathrm{kp} / \mathrm{cm}^{2}$-tan jarri zuen eta ohikoagoa izango zen hormigoiarentzako konpresioaren kontrako erresistentzia bereizgarriarentzat $180 \mathrm{kp} / \mathrm{cm}^{2}$-ko balioa ezarri zuen.

Saiakuntzak egin diren eraikinetan, konpresio-erresistentzien emaitzak 3. taulakoak izan dira.

3. taula. Konpresioaren kontrako batez besteko erresistentzia eta erresistentzia bereizgarria. 1961-1967 bitartean eraikitako eraikinak.

\begin{tabular}{cccll}
\hline $\begin{array}{c}\text { Eraikitako } \\
\text { urtea }\end{array}$ & $\begin{array}{c}\text { Erresistentzia } \\
\text { bereizgarria } \\
\mathrm{N} / \mathrm{mm}^{2}\end{array}$ & $\begin{array}{c}\text { Batez besteko } \\
\mathrm{N} / \mathrm{mm}^{2}\end{array}$ & \multicolumn{1}{c}{ Eraikina } & \multicolumn{1}{c}{$\begin{array}{c}\text { Txostenaren } \\
\text { jatorria [1] }\end{array}$} \\
\hline 1961 & 13,00 & 14,54 & $\begin{array}{l}\text { Etxebizitza eraikina } \\
\text { (Arrasate) }\end{array}$ & $\begin{array}{l}\text { Santamaria et al., } \\
\text { GIKESA }\end{array}$ \\
\hline 1962 & 14,10 & 15,66 & $\begin{array}{l}\text { Jakintza Ikastola } \\
\text { (Donostia) }\end{array}$ & $\begin{array}{l}\text { Losañez et al., } \\
\text { GIKESA }\end{array}$ \\
\hline 1963 & 14,21 & 17,00 & $\begin{array}{l}\text { Etxebizitza eraikina } \\
\text { (Elgoibar) }\end{array}$ & $\begin{array}{l}\text { Losañez et al., } \\
\text { GIKESA }\end{array}$ \\
\hline 1965 & 15,52 & 19,25 & $\begin{array}{l}\text { Etxebizitza eraikina } \\
\text { (Donostia) }\end{array}$ & $\begin{array}{l}\text { Araquistain et al., } \\
\text { GIKESA }\end{array}$ \\
\hline 1967 & 14,85 & 20,27 & $\begin{array}{l}\text { Etxebizitza eraikina } \\
\text { (Donostia) }\end{array}$ & $\begin{array}{l}\text { Araquistain et al., } \\
\text { GIKESA }\end{array}$ \\
\hline 1967 & 15,55 & 18,65 & $\begin{array}{l}\text { Basanoaga Dorrea } \\
\text { (Errenteria) }\end{array}$ & $\begin{array}{l}\text { Losañez et al., } \\
\text { GIKESA }\end{array}$ \\
\hline
\end{tabular}




\section{KALITATE-KONTROLAREN ERREGULAZIOA (EH-73)}

1973an, masako hormigoia edo armatua erabiliko ziren obren proiekturako eta horiek gauzatzeko instrukzioak jaso zituen, bere artikuluen artean, aginduzko balioarekin, hormigoiaren, honen osagaien, altzairuaren eta obra gauzatzearen kalitate-kontrola [11].

Konpresio-erresistentzia bereizgarriaren gutxieneko balioarentzat ezarri zuen balioa $175 \mathrm{kp} / \mathrm{cm}^{2}$-koa izan zen eta gomendatu zuen $250 \mathrm{kp} / \mathrm{cm}^{2}$-koa izan zedila eraikuntzako egituretako hormigoiarentzat.

Ordutik aurrera, gero eta kontrol zorrotzagoak materialaren kalitate kontrastatua eta gaur arteko hobekuntza etengabea bermatu zituen. Horixe frogatzen dute aldi horretan eraikitako eraikinei egindako saiakuntza batzuetan lortutako emaitzek (4. taulan ikus daitezke).

4. taula. Konpresioaren kontrako batez besteko erresistentzia eta erresistentzia bereizgarria. 1973-1978 bitartean eraikitako eraikinak.

\begin{tabular}{cccll}
\hline $\begin{array}{c}\text { Eraikitako } \\
\text { urtea }\end{array}$ & $\begin{array}{c}\text { Erresistentzia } \\
\text { bereizgarria } \\
\text { N/mm }\end{array}$ & $\begin{array}{c}\text { Batez besteko } \\
\text { erresistentzia } \\
\text { N/mm² }\end{array}$ & \multicolumn{1}{c}{ Eraikina } & \multicolumn{1}{c}{$\begin{array}{c}\text { Txostenaren } \\
\text { jatorria [1] }\end{array}$} \\
\hline 1973 & 25,00 & 26,15 & $\begin{array}{l}\text { Etxebizitza eraikina } \\
\text { (Getaria) }\end{array}$ & $\begin{array}{l}\text { Araquistain et al., } \\
\text { GIKESA }\end{array}$ \\
\hline 1976 & 25,65 & 27,22 & $\begin{array}{l}\text { Astigarraga Ikastola } \\
\text { (Astigarraga) }\end{array}$ & $\begin{array}{l}\text { Araquistain et al., } \\
\text { GIKESA }\end{array}$ \\
\hline 1978 & 25,84 & 26,73 & $\begin{array}{l}\text { Etxebizitza eraikina } \\
\text { (Tolosa) }\end{array}$ & $\begin{array}{l}\text { Losañez et al., } \\
\text { GIKESA }\end{array}$ \\
\hline
\end{tabular}

\section{ONDORIOAK}

Hormigoi armatuz Euskal Herrian Xx. mende osoan eraikitako egitura batzuetan egindako saiakuntzen emaitzek frogatzen dute Xx. mendeko 50eko hamarkadaren inguruan erabili ziren hormigoiek akats nabarmenak zituztela, eta atzerapauso nabarmena ekarri zutela, aurreko hormigoiekiko, 4. irudiak erakusten duen bezala.

Hormigoiaren kalitatea aldakorra izan da aldien arabera. Lehenbiziko hormigoi armatuek (1901-1939) konpresio-erresistentzia gero eta handiagoa izateko joera zuten. Izan ere, patenteen eskutik ez ezik, obrako prozedura zorrotz zaintzera zetozen teknikarien begipean egindakoak ziren. Erosiriko sistema bat zen, ardura teknologiko eta zibilarekin. 


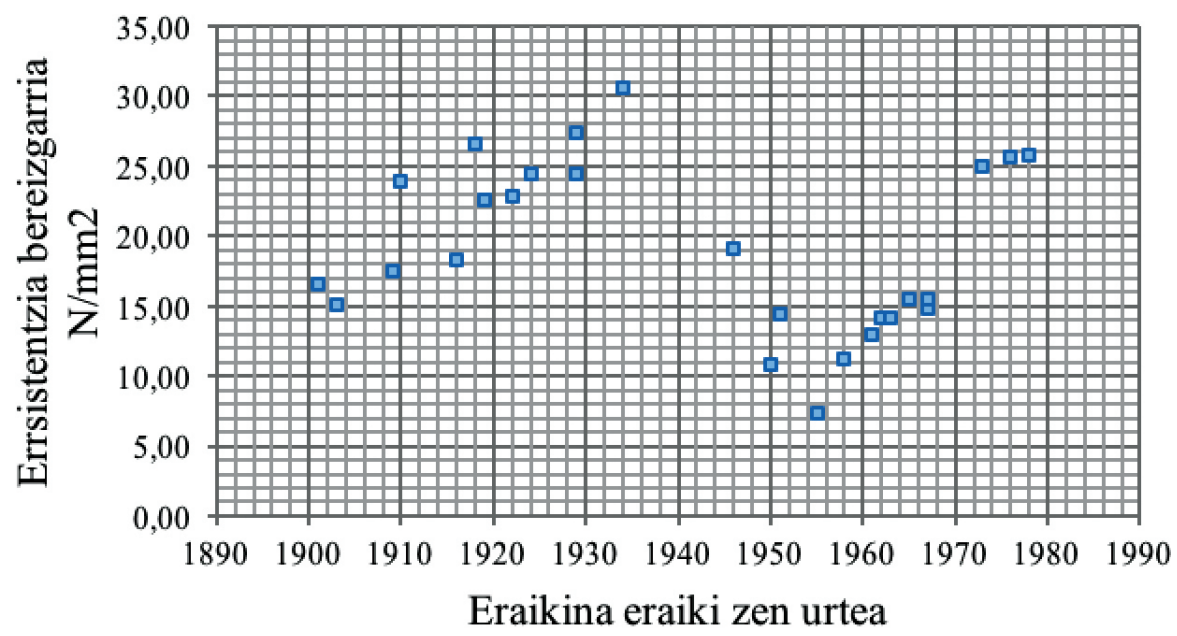

4. irudia. Azterturiko laginen erresistentzia bereizgarria $\mathrm{N} / \mathrm{mm}^{2}$.

Gerraosteko murriztapenen aldian, aldiz, (1939-1960), hormigoiaren kalitateak oso behera egin zuen, erresistentziaren ikuspegitik ez ezik, baita homogeneotasunari, trinkotasunari eta hondamen-koadroei zegokienez ere.

Behin murriztapenen aldia igaro eta gero, eta EH-73 araudia indarrean jarri ostean, konpresio-erresistentzia horren balioa gorantz egiten hasi zen, eta 70eko hamarkadaren erdira iristerako, berreskuratuak zituen hormigoiak gerra aurretik erakutsitako erresistentzia-balioak.

Nolanahi ere, bai hastapeneko sistemetan eta patenteetan, bai gerraostean eta bai 70eko hastapen-urteetan, erresistentzia bereizgarrien arteko aldeak, garai bereko eta inguru geografiko bertsuko hormigoietan ere, handiak eta gorabeheratsuak ziren,.

Izan ere, materialaren kalitatea kontrolatzen hasi zen garaia iritsi arte, ez zen hormigoiaren kalitatearen hobekuntza egonkortzen hasiko, ez eta erresistentziari buruzko datuak antzekoak izaten hasiko; hala erakusten dute kontsultaturiko saiakuntza-datuek: EH-73 Araudia indarrean jarri zenez geroztik, konpresio-erresistentzia guztiz egonkortu zela.

Hortaz, emaitza horiek frogatzen dute ezinezkoa dela materialaren bilakaera linealki irakurtzea eta paradoxa honetara iritsi gara: duela 100 urteko hormigoi baten erresistentzia eta gaur egun duen egoera izan daitezkeela duela 60 urteko hormigoi batenak baino askoz hobeak. 


\section{BIBLIOGRAFIA}

[1] Aztertutako eraikinei buruz eskuratutako datuak GIKESA eta LABEIN, entsegu laborategien laguntzari esker lortu dira.

[2] AREILZA, J. M. de. 1940. Directrices de la nueva ordenación económica, Problemastécnicos de importancia económica en la nueva organización de España. Bartzelonako Unibertsitatea, Bartzelona. 475-503.

[3] MARCOS, I.. 2014. Características constructivas de estructuras de hormigón armado prenormativo. Aprendizaje y metodología de estudio orientadas a su rehabilitación. Doktorego tesi argitaragabea, Euskal Herriko Unibertsitatea, Bilbo.

[4] GOBERNUKO PRESIDENTZIA, Espainiako Estatua. 1941. «Reglamento sobre las restricciones del uso del hierro en edificación». BOE (1941/03/12). 71. 1766-1767

[5] 1943ko uztailaren 8ko AGINDUA eraikinen eraikuntzan burdinazko materialak erabiltzeari buruzkoa.BOE (1943/07/10).191.6651-6652

[6] AZPILICUETA, E.. 2004. La construcción de la arquitectura de posguerraen España (1939-1962). Doktorego tesi argitaragabea, Madrilgo Unibertsitate Politeknikoa, Madril.

[7] NADAL, J. 1959. «Servicios del Instituto en relación con las condiciones técnicas de la construcciónen el momento actual», Informes de la Construcción. 116. 65-72.

1943ko urtarrilan argitaratua: «Circular por la queseseñalannormas sobre la distribución del cemento para el año 1943». DGA buletina. 41-42.

[8] 1941eko martxoaren 12ko dekretuaren ondorioz, legez ezinezkoa izan zen, ia kasu guztietan, metalezko egiturekin eraikitzea: eraikineko metro kuboko zazpi eta hamar kilo burdinara mugatu beharrak, obra ofizialetan eta partikularretan hurrenez hurren, nahikoa ziren baztertuak izateko eta haien ordez hormigoi armatuzko egituretara jotzea.

[9] 1956/01/19ko Dekretua, altzairuaren erabilerari 1941/03/11ko Dekretuak ezarritako murriztapenak kentzen zituena. BOE (1956/01/22). 22. 531.

[10] GOMEZ HERMOSO, J. 1997. Análisis técnico-económico de la influencia que presenta el empleo de diferentes materiales y tipologías estructurales en el proyecto de estructuras de edificios. Doktorego tesi argitaragabea. Madrilgo Unibertsitate Politeknikoa. Madril.

[11] GOBERNUKO PRESIDENTZIA, Espainiako Estatua. 1968. «Instrucción para el proyecto y la ejecución de obras de hormigón en masa o armado». BOE (1968/12/03). 290. 17257-17291. 